\title{
Talk2Practice : Utilização de Reconhecimento e Sintetização de Voz para Prática da Pronúncia da Língua Inglesa
}

\author{
Valéria F. Martins ${ }^{1}$,Luanda da Silva ${ }^{1}$,Eduardo Lombardi ${ }^{1}$, Marcelo P. Guimarães ${ }^{2}$ \\ ${ }^{1}$ Faculdade de Computação e Informática - Universidade Presbiteriana Mackenzie \\ Rua da Consolação, 930 Cep 01302-907 - Consolação - São Paulo - SP - Brasil \\ ${ }^{2}$ Universidade Aberta do Brasil - Universidade Federal de São Paulo (UAB/Unifesp) \\ /Programa de mestrado da Faculdade Campo Limpo Paulista, São Paulo, Brasil. \\ valfarinazzo@hotmail.com, u.luanafelix@gmail.com, eduardolomb@gmail.com \\ marcelodepaiva@gmail.com
}

\begin{abstract}
Resumo. Sistemas com reconhecimento e sintetização de voz estão cada vez mais presentes como meio de interação entre computadores e pessoas. Este artigo apresenta o Talk2Practice, um aplicativo para dispositivos móveis, que utiliza reconhecimento e síntese de voz para auxiliar na prática da pronúncia da Língua Inglesa. A fim de avaliar a usabilidade do aplicativo, foram realizados testes com 19 usuários. Nestes testes, foi obtido o resultado de $83 \%$ de acerto do reconhecimento de voz além da avaliação dos usuários sobre a usabilidade do sistema.
\end{abstract}

\begin{abstract}
Recognition and voice synthesis systems are increasing their use as way of interaction between people and computers. This paper presents the Talk2Practice, an application for mobile devices that uses voice recognition and synthesis to support the practice of English pronunciation. In order to evaluate the usability of the application, tests were performed with 19 users. In these tests, $83 \%$ efficiency of speech recognition was obtained. The tests also allowed to assess the usability of the system.
\end{abstract}

\section{Introdução}

Algumas pessoas buscam por cursos de Inglês em países de Língua Inglesa e, assim, conseguem a imersão. Outros se matriculam em cursos online, geralmente pagos, proferidos por professores nativos destes países. Contudo, estas soluções envolvem custos e são inviáveis para grande parte da população.

Uma opção para auxiliar o processo de aprimoramento da pronúncia menos dispendiosa é a utilização de aplicações com recursos de reconhecimento e síntese de voz que procuram entender o que uma pessoa fala. Com a proliferação dos dispositivos móveis, torna-se conveniente que estes recursos estejam incorporados a eles, tornandoos ubíquos. Como esses equipamentos fazem parte cada vez mais do cotidiano dos alunos, então é oportuno que os professores os usem para favorecer o processo de ensino-aprendizagem. 
Este artigo tem como objetivo apresentar o aplicativo Talk2Practice, que visa auxiliar os alunos no processo de aprimoramento de pronúncia da Língua Inglesa. Ele agrega tecnologias de reconhecimento e síntese de voz em ambientes operacionais de dispositivos móveis, no caso, a plataforma iOS, como iPhone, iPad e iPod Touch. Nele, o professor cria atividades específicas, o que o torna uma extensão de ensino do idioma que é realizado em classe. Esse aplicativo foi avaliado por 3 professores e 16 alunos.

O restante deste artigo está organizado da seguinte forma: a seção 2 apresenta uma revisão dos trabalhos relacionados ao foco desta pesquisa; a seção 3 apresenta os detalhes de implementação do Talk2Practice; a seção 4 apresenta o resultado da avaliação realizada e, por fim, a seção 5 aborda as conclusões.

\section{Trabalhos e aplicativos relacionados}

Foram encontrados alguns trabalhos que utilizam sintetização e reconhecimento de voz como ferramenta de interação humano-computador. Martins e Brasiliano (2012) apresentaram o Voice User Aplication, que visa auxiliar o aprendizado de língua estrangeira baseada em sintetização e reconhecimento de voz. Essa aplicação busca auxiliar a compreensão da escuta e correta pronúncia de palavras. Outro projeto é o Meety [Cocciolo 2009], que tem como objetivo de aprimorar e enriquecer o ensino em sala de aula, capturando as expressões verbais de cada aluno e fornecendo recursos relacionados ao contexto em tempo real. Ehsani e Knodt (1998) apresentaram o Fluency, que treina prosódia assim como fonética.

Além dos trabalhos relacionados, existem, no mercado, aplicativos destinados à aprendizagem de diversas línguas estrangeiras, com diferentes características e métodos de aprendizagem. Como, por exemplo, o Duolingo [Duolingo 2014], que trabalha com atividades relacionadas à escuta, escrita e fala e é capaz de reconhecer e validar a pronúncia de palavras e frases curtas; e o Babbel [Lesson 2014], que além de trabalhar a leitura e a escrita do idioma escolhido, possui sistema de reconhecimento de voz para avaliar a pronúncia do usuário.

\section{Talk2Practice}

O Talk2Practice foi desenvolvido para a plataforma iOS, assim executa em dispositivos como iPhone, iPad e iPod Touch. Ele implementa um modelo pedagógico definido pelo professor que permite que as atividades sejam livremente percorridas, ou seja, de maneira não linear [Behar 2009]. Para isso, o sistema atende aos seguintes requisitos funcionais:

- Suporte a dois perfis de usuários: a) Aluno - acessa o conteúdo dos módulos (por exemplo: animais, roupas, restaurantes e saudações) e as respectivas atividades cadastradas (exercícios sobre o conteúdo do módulo); b) Professor - cadastra, edita ou remove as atividades e módulos;

- O acesso ao sistema é controlado por intermédio do identificador (login), que pode ser uma conta nova ou uma conta do Facebook;

- Somente professores podem alterar, incluir e excluir atividades e módulos;

- As atividades podem ser cadastradas pelos professores utilizando a síntese de voz a partir do texto inserido ou via gravação de voz; 
- Uma atividade pode estar associada a mais de uma resposta válida;

- Cada atividade está associada a uma pontuação;

- Cada aluno possui até três tentativas para responder cada atividade;

- Os alunos podem inserir comentários sobre cada atividade;

- Sempre que uma atividade for respondida, o aluno receberá um retorno (correto/incorreto) e visualizará sua pontuação;

- Os alunos podem navegar de forma não linear nas atividades disponíveis;

- A ajuda da ferramenta proverá o manual de utilização do aplicativo.

O Talk2Practice foi implementado utilizando a linguagem de programação Objective-C. O banco de dados (MySQL) dessa aplicação foi implementado via um serviço web, o que permite a atualização do mesmo de forma centralizada. Utilizou-se o Dragon Software Developer Kit [Nuance 2014] para implementar o serviço de reconhecimento e síntese de voz. A captura de voz é realizada a partir de um marcador conhecido como endpointer, que determina o início, representado pela vibração da voz do usuário - primeira fase do reconhecimento - e o fim da onda sonora, quando ocorre a captura do silêncio, o que indica o fim da fala. O método de reconhecimento utilizado possui um parâmetro que permite configurá-lo para reconhecer palavras ou frases.

O projeto da interface do Talk2Practice levou em consideração restrições próprias dos dispositivos móveis, como, por exemplo, tela menor quando comparada com a de um computador pessoal e a necessidade de uma navegabilidade intuitiva. A Figura 1(a) mostra a tela de cadastro de professores. A Figura 1(b) apresenta o menu de módulos para a escolha do aluno, que pode ser realizada sem dependências entre eles. A Figura 1(c) mostra como uma atividade, que pertence a um módulo, é apresentada ao aluno. As atividades podem ou não possuir imagens associadas. Na parte superior é apresentada a questão e na parte inferior a resposta. Dependendo da atividade proposta pelo professor, o usuário deverá pronunciar somente uma palavra desejada ou uma frase completa. O retorno da pronúncia (certo ou errado) e as palavras reconhecidas são fornecidas para o aluno sempre após uma nova entrada de voz.

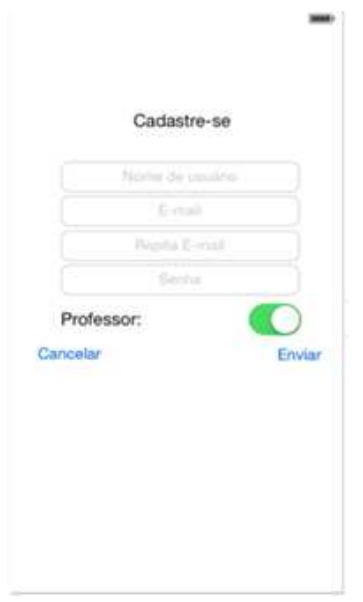

(a)

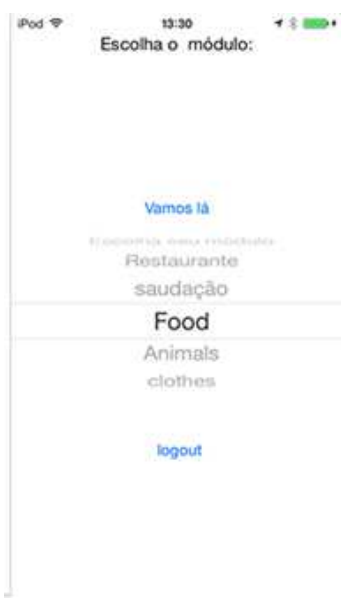

(b)

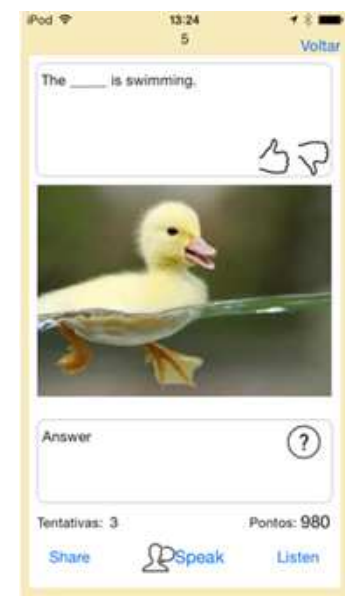

(c)

Figura 1- Interface do Talk2Practice 
Além do foco em validação da pronúncia através do reconhecimento de voz, Talk2Practice foi desenvolvido para funcionar como uma extensão de um curso da Língua Inglesa, no qual o professor cadastra atividades relacionadas à matéria de estudo e as disponibiliza a todos os alunos. Os exercícios podem, por exemplo, ser focados em pontos como o vocabulário, a pronúncia de determinado fonema, seguindo o conteúdo ou modelo pedagógico planejado pelo professor para o ensino. Essas atividades ficam disponíveis a todos os usuários do aplicativo, permitindo a quem não possui uma tutoria também realizar as tarefas.

\section{Testes}

O sucesso do Talk2Practice depende, principalmente, de itens como o reconhecimento e síntese de voz eficiente, acesso ao banco de atividades em tempo satisfatório e da interface de fácil uso. Esse aplicativo foi submetido à avaliação de usuários de professores, que cadastraram e testaram atividades e módulos; e alunos, que realizaram atividades e escreveram comentários (opcional).

\subsection{Perfil dos Professores}

O pré-teste (questionário de perfil) foi aplicado em três professores e indicou que dois eram do sexo feminino e um do masculino. Sendo que um tem idade 18 e 29 anos e dois entre 50 e 59 anos. Um declarou ter nível intermediário no conhecimento da Língua Inglesa e dois declararam ter nível avançado.

Os testes foram realizando no tempo médio de 3 minutos e 55 segundos. Os três professores indicaram satisfação plena com a organização e usabilidade da interface. Dois relataram que o reconhecimento de voz é satisfatório. Dois concordaram que gostariam de utilizar o aplicativo frequentemente. $\mathrm{O}$ professor que respondeu não ter opinião se usaria frequentemente o Talk2Practice, relatou também que o fato de não estar habituado com a plataforma de teste (Smartphone da Apple) foi determinante em sua resposta.

\subsection{Perfil dos Alunos}

Foram realizados testes com dezesseis alunos, com tempo médio de 2 minutos e 57 segundos. Os resultados do questionário do perfil dos alunos mostram que cinco usuários eram do sexo feminino e 11 do masculino. A faixa etária dos usuários foi de $81,25 \%$ entre 18 e 29 anos; $6,25 \%$ entre 30 e 39 anos; e $12,5 \%$ entre 50 e 59 anos. 62,5\% declaram ter nível básico em conhecimento da Língua Inglesa, 37,5\% nível intermediário. No entanto, com relação à pronúncia, $81,25 \%$ dos entrevistados consideram-se com conhecimento básico e $18,25 \%$ com intermediário.

O sistema de reconhecimento do Talk2Practice foi testando com os alunos em ambiente com e sem ruídos. A ordem das palavras testadas foi a mesma para testes de mesmo módulo realizados pelos usuários. Em um ambiente com muito ruído, as simulações não apresentaram resultados satisfatórios (acurácia do reconhecimento ficou abaixo de 50\%). Mesmo em ambientes controlados (silenciosos), o reconhecedor não acertou $100 \%$ das palavras e frases. Nos testes, a acurácia do reconhecedor de voz foi de $83 \%$. Vale a pena destacar que $81,25 \%$ dos alunos concordam que o reconhecimento de 
voz do aplicativo é satisfatório. 87,5\% dos alunos acreditam que gostariam de utilizar o aplicativo frequentemente.

\section{Conclusões}

Os resultados apresentados pelo Talk2Practice evidenciam a viabilidade da utilização de sintetização e reconhecimento de voz em dispositivos móveis para auxiliar a prática da pronúncia da Língua Inglesa. Esse aplicativo possui como diferencial a possibilidade dos professores utilizá-lo como extensão da sala de aula.

Os testes realizados demonstram que o reconhecedor utilizado possui restrições em relação à qualidade do reconhecimento quando utilizado em ambiente com ruído. Ainda assim, o nível de satisfação dos usuários superou as expectativas iniciais.

Sugere-se como trabalhos futuros a criação de novas funcionalidades, como a parametrização do método avaliativo a ser utilizado para cada atividade. Assim, cada professor poderia definir a pontuação de cada atividade conforme o nível de dificuldade. E, por fim, versões de interfaces compatíveis com telas de tamanhos diferentes, como a dos tablets.

\section{Referências}

Behar, P. A. (2009). Modelos Pedagógicos em Educação a Distância. Porto Alegre: Artmed.

Cocciolo, A. (2009). "Using speech recognition technology in the classroom: an experiment in computer-supported collaborative learning". In Proceedings of the 9th international conference on Computer supported collaborative learning-Volume 2 (pp. 103-105). International Society of the Learning Sciences.

Duolingo (2014). https://www.duolingo.com/. Maio.

Ehsani, F., Knodt, E. (1998). "Speech technology in computer-aided language learning: Strengths and limitations of a new CALL paradigm". Language Learning \& Technology, 2(1), 45-60.

Lesson Nine GmbH (2014). “Aprenda inglês facilmente com a Babbel". http://lp.babbel.com/d/POR_index.html?12=ENG. Janeiro.

Martins, V. F. and Brasiliano, A. (2012). "Interface do Usuário Baseada em Voz como Ferramenta para Promover Ensino/Aprendizagem de Língua Estrangeira”, Reavi: Revista Eletrônica do Alto do Vale do Itajaí, [itajaí], v. 1, n. 1, p.34-42, Agosto. Mensal.

Nuance Mobile (2014). "SpeechKit Framework Reference". http://dragonmobile.nuancemobiledeveloper.com/public/Help/SpeechKitFramework Reference_iOS/index.html. Fevereiro. 